\title{
A Novel Rollover Warning Approach for Commercial Vehicles Using Unscented Kalman Filter
}

\author{
Junjian Hou, ${ }^{1}$ Haizhu Lei, ${ }^{1}$ Zhijun Fu $\mathbb{D}^{1},{ }^{1}$ Peixin Yuan, ${ }^{1}$ Yuming Yin $\mathbb{D}^{\circ},{ }^{2}$ Heyang Feng, \\ Zihao Li, ${ }^{1}$ Mingxu Zhang, ${ }^{1}$ Minghui Cui, ${ }^{1}$ and Yuqing $X{ }^{1}$ \\ ${ }^{1}$ Henan Provincial Key Laboratory of Intelligent Manufacturing of Mechanical Equipment, \\ Zhengzhou University of Light Industry, Zhengzhou, China \\ ${ }^{2}$ College of Mechanical Engineering, Zhejiang University of Technology, Hangzhou, China
}

Correspondence should be addressed to Zhijun Fu; fuzhijun2008@163.com

Received 27 August 2021; Accepted 15 December 2021; Published 5 January 2022

Academic Editor: Xianjian Jin

Copyright (C) 2022 Junjian Hou et al. This is an open access article distributed under the Creative Commons Attribution License, which permits unrestricted use, distribution, and reproduction in any medium, provided the original work is properly cited.

Roll responses of the semitrailer and the tractor provide higher lead time and characterise the roll instability of the commercial vehicles subjected to directional manoeuvres at highway speeds. This paper proposes a novel rollover index based on the synthesized roll angles of the tractor and trailer. Owing to the poor measurability, the unscented Kalman filter (UKF) algorithm is used to estimate the roll angle of the track and trailer, respectively. Meanwhile, different weight coefficients are considered in the rollover index to eliminate the influence of mutual coupling between the tractor and the trailer and improve the accuracy of the warning. For the practical implementation of the algorithm, a two-stage rollover warning method triggered by the video and audio is finally proposed to reduce the possibilities of false warnings. Co-simulation is presented to prove the validity of the proposed rollover warning approach.

\section{Introduction}

In heavy-duty semitrailer vehicles, owing to their heavy load, long vehicle body length, and high mass center (CG), the stability is worse compared with other vehicles. Rollover accident is a kind of traffic accident with high casualty rate, especially for semitrailer. The research on the rollover warning system firstly needs to construct a rollover index and then judge whether the rollover index reaches the threshold according to the real-time driving state of the vehicle [1-5].

The semitrailer rollover index can be roughly divided into two categories: static rollover index and dynamic rollover index. The static index mainly refers to the static stability coefficient (SSF) [6], which is defined as the ratio between the width of the half-track and the height of the center of gravity. Although the measurement and calculation are relatively simple, it does not perform well in the dynamic process. Dynamic rollover index is derived by considering the roll responses of different units of an articulated vehicle under dynamic manoeuvre and has been proved to be more reliable compared with the static index. Roll response amplification tendency (RAT) [7] is defined as the ratio of the peak lateral acceleration response of the trailer to the tractor, and its sensitivity to the parameter makes it impossible to reliably predict the rollover. The inherent defect of differential wheel slip (DWS) method [8], which is derived from the measurement of slip difference between left and right wheels, directly leads to poor warning reliability. In [9], the load transfer ratio (LTR) is used to evaluate the limit of dynamic roll stability of heavy vehicles based on lateral load transfer between the outer and inner tires. However, its practical application is too complex and rollovers' threshold is difficult to determine. Rakheja et al. [10] extend the LTR method by designing an improved online prediction algorithm called roll safety factor (RSF), which is defined as the ratio of load transfer of all axles except for the first axis with less contribution to the net restoring moment. The normalised roll response of semitrailer sprung mass (NRSSM) index [11], which incorporates the rearward amplification 
tendency of the combination between the tractor and the trailer, has been proposed as an extension to RSF. The NRSSM index, based on roll responses of the semitrailer sprung mass and the tractor front and rear axles, is thus considered to be a more reliable rollover metric that may also yield reasonably good performance with respect to the sensitivity, reliability, and lead time. However, the roll angle is not easy to measure in practical application. In order to enhance the poor measurability of the dynamic rollover index, many estimation methods such as neural networks [12], Kalman filtering [13-16], and least square [17] are used to estimate the relevant key state variables in the rollover index online.

This study proposes a novel online rollover index based on the composite roll angles of the tractor and the trailer of semitrailer commercial vehicles. The unscented Kalman filter (UKF) algorithm is used to estimate the roll angle of the track and trailer, respectively. With combination of the rollover index and the semitrailer roll response, a two-stage early warning method triggered by video and audio is finally proposed for the actual algorithm implementation. The effectiveness of the proposed estimation method is illustrated under different directional manoeuvres using the TruckSim and simulation platform. The notable contributions of the study include (i) the synthesis of an rollover index based on the roll angles of the tractor and trailer to achieve higher accuracy and reliability, (ii) an UKF algorithm is used to estimate the roll angles of the tractor and trailer to enhance the measurability, and (iii) design of the two-stage warning method that relies only on roll response of the commercial vehicles and triggered by video and audio, which generally reduce the possibilities of false warnings.

The remainder of this paper is organized as follows. In Section 2, the seven-degree-of-freedom model of the semitrailer is given. A new rollover index is introduced in Section 3. Section 4 presents the unscented Kalman filter algorithm for estimating the roll angle of the semitrailer vehicle. The simulation results are shown in Section 5, and the conclusions for the whole paper are drawn in Section 6.

\section{Vehicle Dynamics Model}

In the actual driving process, the dynamic characteristics of the semitrailer are very complex. In this paper, we choose the commonly used five-axle tractor-semitrailer vehicle $[18,19]$ as the baseline commercial vehicle. In order to facilitate analysis, the three rear axles of the trailer are equivalent to one axle and make the following assumptions:

(1) The vehicle tire model is assumed to be linear

(2) The influence of suspension deformation and body roll on wheel steering and tire characteristics is not considered

(3) The longitudinal speed of the vehicle is constant, and the influence of aerodynamics and road slope is ignored
(4) The steering wheel angle is directly taken as the input of the vehicle model, and the left and right wheel angles are assumed to be approximately equal

(5) Taking the vehicle reference coordinate system as the reference, the model considers the vehicle lateral, yaw, roll, and hinged motion in four directions and ignores the vertical motion along the $Z$-axis and the pitch motion along the $Y$-axis

(6) Ignore the roll motion of the nonsuspension mass and its influence on the wheel

Based on the above assumptions, a single-track sevendegree-of-freedom (7-DOF) vehicle dynamics model is established as shown in Figure 1. The DOFS are yaw motion of the tractor, lateral motion of the tractor, roll motion of the tractor, yaw motion of the trailer, lateral motion of the trailer, roll motion of the trailer, and articulated motion of the tractor and the trailer.

Next, the detailed mathematical modeling process of the 7-DOF model is presented. The lateral force equation of the tractor is

$$
\sum F_{Y 1}=m_{1} a_{y 1}-m_{1 s} a_{y}
$$

where $a_{y}$ represents the centrifugal acceleration of the sprung mass of tractor and can be expressed as $a_{y}=\left(h_{1} \cdot \dot{\phi}_{1}\right)^{\prime}=h_{1} \cdot \ddot{\phi}_{1}$; the corresponding lateral acceleration component is expressed as $a_{y 1}=\dot{v}_{1}+u_{1} \omega_{r 1}$.

Side slip angle of the tractor can be described as $\beta_{1}=v_{1} / u_{1}$. With the assumption that the vehicle's longitudinal speed remains constant, i.e., $\dot{u}_{1}=0$, we obviously have $\dot{\beta}_{1}=\left(v_{1} / u_{1}\right)^{\prime}=\dot{v}_{1} / u_{1}, \dot{v}_{1}=\dot{\beta}_{1} \cdot u_{1}$. Then, $(1)$ can be further rewritten as

$$
\sum F_{Y 1}=m_{1} u_{1}\left(\dot{\beta}_{1}+\omega_{r 1}\right)-m_{1 s} h_{1} \ddot{\phi}_{1} \text {. }
$$

The moment of inertia of the tractor on the $Z$-axis can be described as

$$
\sum M_{Z 1}=I_{1 z z} \dot{\omega}_{r 1}-I_{1 x z} \ddot{\phi}_{1}
$$

The moment of inertia of the tractor on the $X$-axis can be defined as

$$
\sum M_{X 1}=I_{1 x x} \ddot{\phi}_{1}+m_{1 s} a_{y} h_{1}-I_{1 x z} \dot{\omega}_{r 1} .
$$

By substituting $a_{y}=\left(h_{1} \cdot \dot{\phi}_{1}\right)^{\prime}=h_{1} \cdot \ddot{\phi}_{1}$ into equation (4), we have

$$
\sum M_{X 1}=\left(I_{1 x x}+m_{1 s} h_{1}^{2}\right) \ddot{\phi}_{1}-I_{1 x z} \dot{\omega}_{r 1} .
$$

The dynamic equations of the tractor can be obtained by synthesizing equations (2), (3), and (5), such that

$$
\left\{\begin{array}{l}
\sum F_{Y 1}=m_{1} u_{1}\left(\dot{\beta}_{1}+\omega_{r 1}\right)-m_{1 s} h_{1} \ddot{\phi}_{1} \\
\sum M_{Z 1}=I_{1 z z} \dot{\omega}_{r 1}-I_{1 x z} \ddot{\phi}_{1} \\
\sum M_{X 1}=\left(I_{1 x x}+m_{1 s} h_{1}^{2}\right) \ddot{\phi}_{1}-I_{1 x z} \dot{\omega}_{r 1}
\end{array}\right.
$$

Similarly, the dynamic equations of the trailer can be derived as 


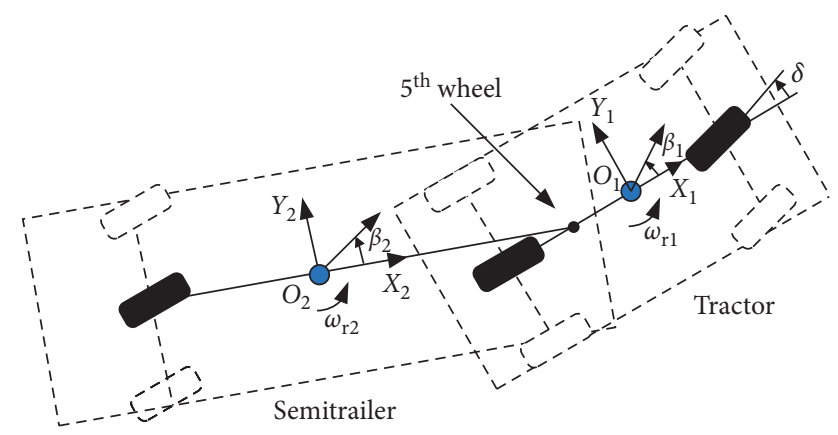

(a)

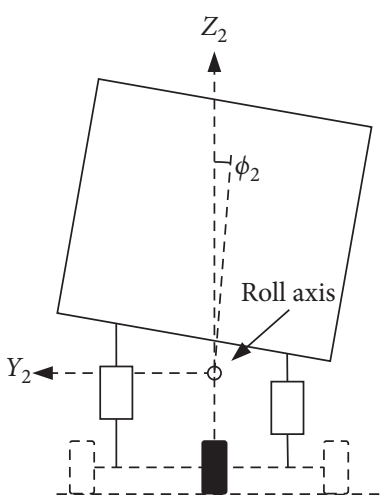

(b)

Figure 1: Semitrailer vehicle system: (a) top view of tractor semitrailer; (b) rear view of semitrailer.

$$
\left\{\begin{array}{l}
\sum F_{Y 2}=m_{2} u_{2}\left(\dot{\beta}_{2}+\omega_{r 2}\right)-m_{2 s} h_{2} \ddot{\phi}_{2} \\
\sum M_{Z 2}=I_{2 z z} \dot{\omega}_{r 2}-I_{2 x z} \ddot{\phi}_{2} \\
\left.\sum M_{X 2}=\left(I_{2 x x}+m_{2 s} h_{2}^{2}\right)\right) \ddot{\phi}_{2}-I_{2 x z} \dot{\omega}_{r 2}
\end{array}\right.
$$

Assuming that the front wheel angle and roll angle are small, the external force of the tractor can be expressed as

$$
\left\{\begin{array}{l}
\sum F_{Y 1}=F_{y 1}+F_{y 2}+F_{y 4} \\
\sum M_{Z 1}=F_{y 1} a-F_{y 2} b-F_{y 4} c \\
\sum M_{X 1}=m_{1 s} g h_{1} \phi_{1}+m_{1 s} a_{y y 1} h_{1}-k_{r 1} \phi_{1}-c_{1} \dot{\phi}_{1}+k_{12}\left(\phi_{2}-\phi_{1}\right)-F_{y 4} h_{1 c}
\end{array} .\right.
$$

Furthermore, consider the case when the articulation angle is small; the resultant external force of the trailer can be described as

$$
\left\{\begin{array}{l}
\sum F_{Y 2}=F_{y 3}-F_{y 4} \\
\sum M_{Z 2}=-F_{y 3} d-F_{y 4} e \\
\sum M_{X 2}=m_{2 s} g h_{2} \phi_{2}+m_{1 s} a_{y y 2} h_{2}-k_{r 2} \phi_{2}-c_{2} \dot{\phi}_{2}-k_{12}\left(\phi_{2}-\phi_{1}\right)+F_{y 4} h_{1 c}
\end{array},\right.
$$

where $a_{y y 1}$ and $a_{y y 2}$ represent the sprung mass lateral acceleration of the tractor and semitrailer, respectively; $a_{y y 1}=u_{1}\left(\dot{\beta}_{1}+\omega_{r 1}\right)-h_{1} \ddot{\phi}_{1}$.

In this paper, the linear tire model is adopted to analyse the force of each tire. The lateral force on each axis and the cornering force on each tire are assumed to be equal; the tire's cornering force can thus be depicted as

$$
\left\{\begin{array}{l}
F_{y 1}=k_{1} \alpha_{1} \\
F_{y 2}=k_{2} \alpha_{2} \\
F_{y 3}=k_{3} \alpha_{3}
\end{array}\right.
$$

Using $\delta$ to represent the front wheel angle, then the tire slip angle is defined as

$$
\left\{\begin{array}{l}
\alpha_{1}=\frac{v_{1}+\omega_{r 1} a}{u_{1}}-\delta=\beta_{1}+\frac{a \omega_{r 1}}{u_{1}}-\delta \\
\alpha_{2}=\frac{v_{1}-\omega_{r 1} b}{u_{1}}=\beta_{1}-\frac{b \omega_{r 1}}{u_{1}} \\
\alpha_{3}=\frac{v_{2}-\omega_{r 2} d}{u_{2}}=\beta_{2}-\frac{d \omega_{r 2}}{u_{2}}
\end{array}\right.
$$


In case that there is no speed difference between the tractor and the trailer, i.e., $u_{1}=u_{2}=u$, then the cornering force of each tire can be expressed as

$$
\left\{\begin{array}{l}
F_{y 1}=k_{1}\left(\beta_{1}+\frac{a \omega_{r 1}}{u}-\delta\right) \\
F_{y 2}=k_{2}\left(\beta_{1}-\frac{b \omega_{r 1}}{u}\right) \\
F_{y 3}=k_{3}\left(\beta_{2}-\frac{d \omega_{r 2}}{u}\right)
\end{array}\right.
$$

Combining with the above analysis, the full vehicle dynamics equation of the semitrailer shown in Figure 1 is shown as follows:

$$
\left\{\begin{array}{l}
m_{1} u\left(\dot{\beta}_{1}+\omega_{r 1}\right)-m_{1 s} h_{1} \ddot{\phi}_{1}=k_{1}\left(\beta_{1}+\frac{a \omega_{r 1}}{u}-\delta\right)+k_{2}\left(\beta_{1}-\frac{b \omega_{r 1}}{u}\right)+F_{y 4} \\
I_{1 z z} \dot{\omega}_{r 1}-I_{1 x z} \ddot{\phi}_{1}=a k_{1}\left(\beta_{1}+\frac{a \omega_{r 1}}{u}-\delta\right)-b k_{2}\left(\beta_{1}-\frac{b \omega_{r 1}}{u}\right)-c F_{y 4} \\
\left(I_{1 x x}+m_{1 s} h_{1}^{2}\right) \ddot{\phi}_{1}-I_{1 x z} \dot{\omega}_{r 1}=m_{1 s} g h_{1} \phi_{1}+m_{1 s} h_{1}\left[u\left(\dot{\beta}_{1}+\omega_{r 1}\right)-h_{1} \ddot{\phi}\right]_{1}-k_{r 1} \phi_{1}-c_{1} \dot{\phi}_{1}+k_{12}\left(\phi_{2}-\phi_{1}\right)-F_{y 4} h_{1 c} \\
m_{2} u\left(\dot{\beta}_{2}+\omega_{r 2}\right)-m_{2 s} h_{2} \ddot{\phi}_{2}=k_{3}\left(\beta_{2}-\frac{d \omega_{r 2}}{u}\right)-F_{y 4} \\
I_{2 z z} \dot{\omega}_{r 2}-I_{2 x z} \ddot{\phi}_{2}=-d k_{3}\left(\beta_{2}-\frac{d \omega_{r 2}}{u}\right)-e F_{y 4} \\
\left(I_{2 x x}+m_{2 s} h_{2}^{2}\right) \ddot{\phi}_{2}-I_{2 x z} \dot{\omega}_{r 2}=m_{2 s} g h_{2} \phi_{2}+m_{2 s} h_{2}\left[u\left(\dot{\beta}_{2}+\omega_{r 2}\right)-h_{2} \ddot{\phi}_{2}\right]-k_{r 2} \phi_{2}-c_{2} \dot{\phi}_{2}-k_{12}\left(\phi_{2}-\phi_{1}\right)+F_{y 4} h_{2 c} \\
\dot{\beta}_{1}-\dot{\beta}_{2}-\frac{h_{1 c}}{u} \ddot{\phi}_{1}+\frac{h_{2 c} \ddot{\phi}_{2}-\frac{c}{u} \dot{\omega}_{r 1}-\frac{e}{u} \dot{\omega}_{r 2}+\omega_{r 1}-\omega_{r 2}=0}{u}
\end{array} .\right.
$$

\section{Rollover Index Design}

Rollover index is a real-time dynamic factor indicating the likelihood of a rollover and is used to trigger the controller to prevent rollover. It is well known that the most basic indicator of rover index is the lateral load transfer ratio (LTR), which is defined as the normal load between the left and right tires caused by the rolling motion of the vehicle, such that

$$
L T R=\frac{F_{L}-F_{R}}{F_{L}+F_{R}},
$$

where $R$ denotes the rollover index.

Clearly, from equation (14), we know that rollover index $R$ varies in the interval $[-1,1]$. When it is either left side or right side of the wheel lift-off, the extreme value is reached, and for a perfectly symmetric commercial vehicle with the straight manoeuvres, it is 0 . For semitrailers, since the first axle (the front axle of the tractor) does not contribute much to the net restoring torque [11], the first axle is thus omitted from the LTR, so the roll safety factor (RSF) is defined as follows:

$$
R S F=\left|\frac{\sum_{j=1}^{m}\left(F L_{j}-F R_{j}\right)}{\sum_{j=1}^{m}\left(F L_{j}+F R_{j}\right)}\right|,
$$

where $m$ represents the number of axles remaining after removing the first axle.

However, equation (15) cannot be applied directly in practice due to the fact that the vertical force cannot be obtained by actual measurement. Therefore, it is necessary to propose a rollover index with simple measurement, low cost, and accurate warning, and equation (15) can be used as theoretical reference value to compare and evaluate the proposed rollover index. In [11], the performance characteristics of various potential measures related to onset of a manoeuvre-induced rollover are investigated in terms of 
their reliability, measurability, and lead time, where the results suggest that roll angle is directly related to the relative rollover condition and may thus be considered as the most reliable measure, irrespective of the vehicle configuration and design and operating variables. In view of this fact, this paper proposes a new roll index RI as follows:

$$
R I=x \times R I_{1}+y \times R I_{2},
$$

with

$$
\begin{aligned}
& R I_{1}=\frac{2 h_{1}}{g l_{w 1}} a_{y 1}+\frac{2 h_{1}}{l_{w 1}} \phi_{1}, \\
& R I_{2}=\frac{2 h_{2}}{g l_{w 2}} a_{y 2}+\frac{2 h_{2}}{l_{w 2}} \phi_{2},
\end{aligned}
$$

where $l_{w 1}$ and $l_{w 2}$ represent the wheelbase of the tractor and the trailer, $a_{y 1}$ and $a_{y 2}$ denote the lateral acceleration of the tractor and the trailer, respectively, and $x$ and $y$ represent different weight coefficients of the tractor and the trailer contributing to the total rollover index.

Remark 1. Note from (17) that the rollover index mainly depends on the state variables as $a_{y 1}, a_{y 2}, \phi_{1}, \phi_{2}, h_{1}$, and $h_{2}$. Lateral accelerations $a_{y 1}$ and $a_{y 2}$ can be obtained via a sensor measurement. Center of gravity height $h$ is usually assumed to be a prior constant $[20,21]$ or can be estimated online [22]. However, there is no effective method available to measure roll angles $\phi_{1}$ and $\phi_{2}$. The commonly used way is to measure the roll angular velocity via the gyroscope, and then, the roll angular velocity is integrated to finally obtain the roll angle, but this method could enlarge the gain error of the sensor and lead to inaccurate results. Therefore, in order to obtain the roll angle of the tractor and trailer, this paper will use UKF algorithm to estimate the roll angle of the tractor and trailer online in real time, respectively. The detailed analytical results will be given in Section 4 .

\section{Unscented Kalman Filter Estimate Algorithm}

Kalman filter is one of the most important and common estimation algorithms. Extend Kalman filter (EKF), in which state distribution is propagated analytically by first-order linearization of nonlinear systems, has been developed as an extension to the Kalman filter. However, the posterior mean and covariance may be corrupted in EKF. The UKF [23], which is a derivative-free alternative to EKF, overcomes this problem by using a deterministic sampling approach. The state distribution is represented using a minimal set of carefully chosen sample points called sigma points. UKF has been proved to be a more effective way to deal with the nonlinear state estimation problem. Details of the estimation of roll angle based on UKF are described below.

Firstly, the estimation model is established according to equation (13). Select the vectors in terms with the vehicle states and observed measurement as $x=\left[\phi_{1}, \dot{\phi}_{1}, \ddot{\phi}_{1}, \phi_{2}, \dot{\phi}_{2}, \ddot{\phi}_{2}\right]^{T}$ and $y=\left[\dot{\phi}_{1}, \ddot{\phi}_{1}, \dot{\phi}_{2}, \ddot{\phi}_{2}\right]^{T}$, respectively. The parameters for simulation are set as follows: process noise covariance matrix $Q=1 e 8 \times I_{4}$, measurement noise covariance matrix $R=1 \times I_{3}$, initial state of the system $x_{0}=[0,0,0,0,0,0]^{T}$, and initial covariance matrix $P_{0}=I_{6}$, where $I$ represents the unit matrix.

Then, the state space equation of the system is derived as follows:

$$
\begin{aligned}
& x_{k}=f_{k}\left(x_{k-1}, u_{k-1}\right)+w_{k}, \\
& y_{k}=H x_{k-1}+v_{k},
\end{aligned}
$$

with

$$
\begin{aligned}
f_{k}\left(x_{k-1}, u_{k-1}\right) & =\left[\begin{array}{cc}
\left(I_{1 x x} x(3)-m_{1} a_{y 1} h_{1}+C R_{1}(x(2)+t \Delta n T q \times h x(3))\right) /\left(m_{1} g h_{1}-K R_{1}\right) \\
x(2)+\Delta T \times x(3) \\
\left(I_{2 x x} x(6)-m_{2} a_{y 2} h_{2}+C R_{2}(x(5)+t \Delta n T q \times h x(6))\right) /\left(m_{2} g h_{2}-K R_{2}\right) \\
x(5)+\Delta T \times x(6) \\
x(6)
\end{array}\right], \\
H & =\left[\begin{array}{cccccc}
0 & 1 & 0 & 0 & 0 & 0 \\
0 & 0 & 1 & 0 & 0 & 0 \\
0 & 0 & 0 & 0 & 1 & 0 \\
0 & 0 & 0 & 0 & 0 & 1
\end{array}\right],
\end{aligned}
$$

where $f(x, u)$ is the state transition equation, $\mathrm{H}$ is the coefficient matrix of the observation equation, and $w_{k}$ and $v_{k}$ denote process noise and observation noise, respectively, which are assumed to be Gaussian white noise. The basic flowchart of the UKF algorithm is shown in Figure 2.
The statistical characteristics of $y$ are calculated by unscented transform (UT) when state mean $\bar{x}$ and variance $P$ are known. The sigma point is selected using a symmetrical distribution sampling strategy.

Calculate $2 n+1$ sigma sampling points, such that 


$$
\begin{aligned}
& X^{(0)}=\bar{X}, i=0 \\
& X^{(i)}=\bar{X}+(\sqrt{(n+\lambda) P})_{i}, i=1 \sim n, \\
& X^{(i)}=\bar{X}-(\sqrt{(n+\lambda) P})_{i}, i=n+1 \sim 2 n,
\end{aligned}
$$

where $(\sqrt{P})_{i}$ represents the $i$ th column of the square root of a matrix.

Calculate the corresponding weight of the sampling point as

$$
\begin{aligned}
& \omega_{m}^{(0)}=\frac{\lambda}{n+\lambda}, \\
& \omega_{c}^{(0)}=\frac{\lambda}{n+\lambda}+\left(1-\alpha^{2}+\beta\right), \\
& \omega_{m}^{(i)}=\omega_{c}^{(i)}=\frac{\lambda}{2(n+\lambda)}, \quad 5 i=1 \sim 2 n,
\end{aligned}
$$

where $m$ represents the mean, $c$ represents the covariance, and $i$ represents the number of sampling points. Parameter $\lambda=\alpha^{2}(n+\kappa)-n$ is the scaling factor, which can reduce the total prediction error. The small positive number $\alpha$ controls the distribution of sampling points and is selected as 0.01 . Parameter $\kappa$ is usually taken as $0, \beta$ is the nonnegative weighting coefficient, and the value of 2 is the best in Gaussian distribution.

On the premise of the above unscented transformation, the process of UKF is summarized as follows:

Step 1: obtain sigma points and corresponding weights by unscented transformation:

$$
\begin{aligned}
X^{(i)}(k \mid k)= & {[\hat{X}(k \mid k) \hat{X}(k \mid k)} \\
& +\sqrt{(n+\lambda) P(k \mid k)} \hat{X}(k \mid k)-\sqrt{(n+\lambda) P(k \mid k)}] .
\end{aligned}
$$

Step 2: one-step prediction for sigma points:

$$
X^{(i)}(k+1 \mid k)=f\left[k, X^{(i)}(k \mid k)\right] .
$$

Step 3: perform a weighted summation on the one-step prediction of the sigma point to obtain the one-step prediction of the system state quantity and the covariance matrix:

$$
\begin{aligned}
& \widehat{X}(k+1 \mid k)=\sum_{i=0}^{2 n} \omega^{(i)} X^{i}(k+1 \mid k), \\
& P(k+1 \mid k)=\sum_{i=0}^{2 n} \omega^{(i)}\left[\widehat{X}(k+1 \mid k)-X^{(i)}(k+1 \mid k)\right]\left[\widehat{X}(k+1 \mid k)-X^{(i)}(k+1 \mid k)\right]^{T}+Q .
\end{aligned}
$$

Step 4: according to the one-step predicted value, use the unscented transformation again to generate a new sigma point set:

$$
X^{(i)}(k+1 \mid k)=\left[\begin{array}{c}
\hat{X}(k+1 \mid k) \\
\widehat{X}(k+1 \mid k)+\sqrt{(n+\lambda) P(k+1 \mid k)} \\
\widehat{X}(k+1 \mid k)-\sqrt{(n+\lambda) P(k+1 \mid k)}
\end{array}\right] .
$$

Step 5: substitute the newly obtained sigma point set into the observation function to obtain the predicted value of the sigma point set:

$$
Z^{(i)}(k+1 \mid k)=h\left[X^{(i)}(k+1 \mid k)\right]
$$

Step 6: perform a weighted summation of the predicted values of the observation values of the sigma point set obtained in the fifth step to obtain the mean and covariance of the system prediction, such that

$$
\begin{aligned}
\bar{Z}(k+1 \mid k) & =\sum_{i=0}^{2 n} \omega^{(i))} Z^{(i)}(k+1 \mid k), \\
P_{z_{k} z_{k}} & =\sum_{i=0}^{2 n} \omega^{i}\left[Z^{(i)}(k+1 \mid k)-\bar{Z}(k+1 \mid k)\right]\left[Z^{(i)}(k+1 \mid k)-\bar{Z}(k+1 \mid k)\right]^{T}+R, \\
P_{x_{k} z_{k}} & =\sum_{i=0}^{2 n} \omega^{i}\left[X^{(i)}(k+1 \mid k)-\bar{Z}(k+1 \mid k)\right]\left[Z^{(i)}(k+1 \mid k)-\bar{Z}(k+1 \mid k)\right]^{T} .
\end{aligned}
$$




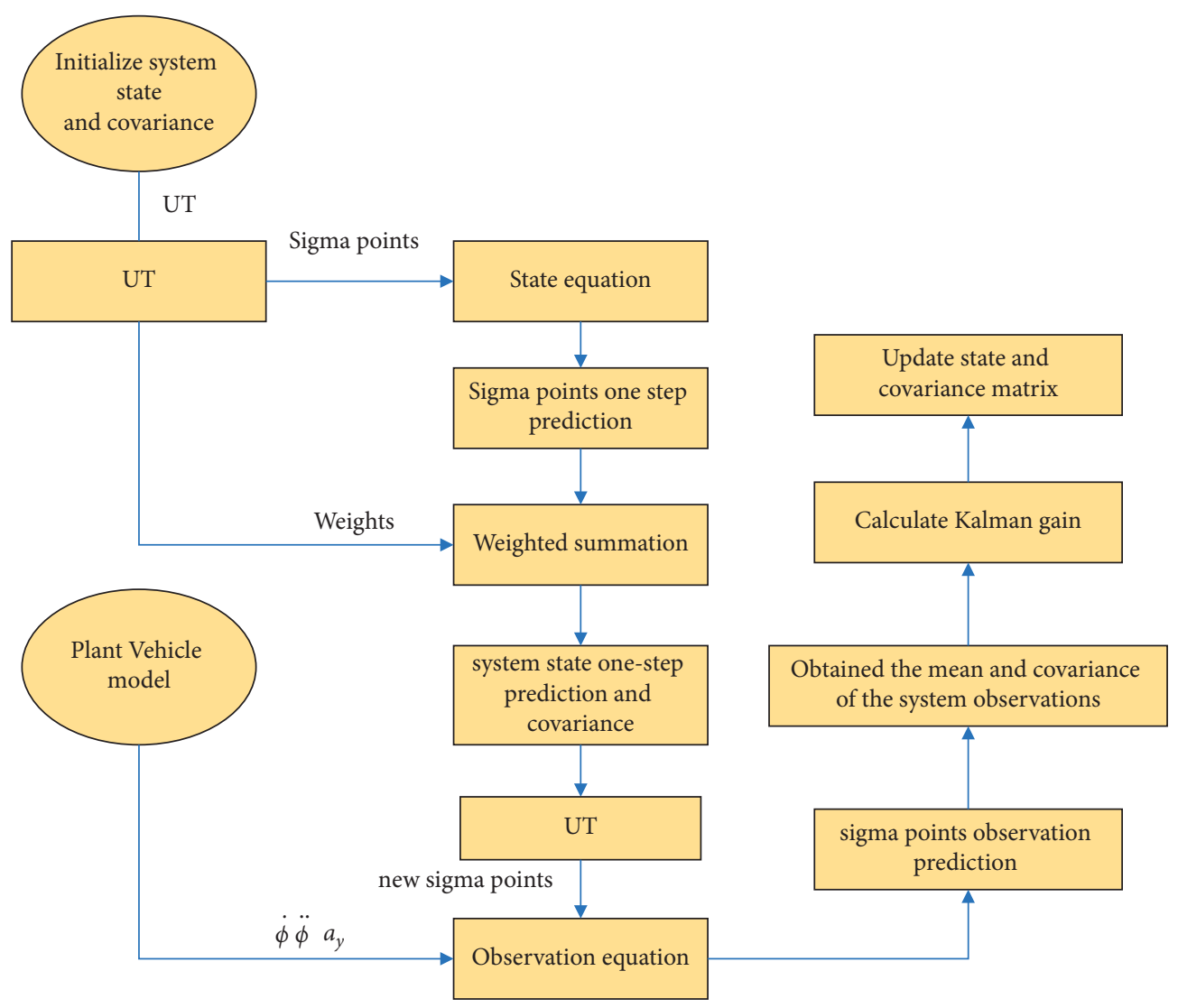

FIGURE 2: UKF algorithm flowchart.

Step7: calculate Kalman gain:

$$
K(k+1)=P_{x_{k} z_{k}} P_{z_{k} z_{k}}^{-1}
$$

Step8: update the state and covariance matrix of the system:

$$
\begin{aligned}
\widehat{X}(k+1 \mid k+1) & =\widehat{X}(k+1 \mid k)+K(k+1)[Z(k+1)-\widehat{Z}(k+1 \mid k)] . \\
P(k+1 \mid k+1) & =P(k+1 \mid k)+K(k+1) P_{z_{k} z_{k}} K^{T}(k+1),
\end{aligned}
$$

\section{Simulation and Implementation Discussion}

5.1. Simulation. The proposed rollover warning approach for commercial vehicles using unscented Kalman filter estimation algorithm is implemented in the TruckSim software together with Matlab/Simulink, where the co-simulation diagram is shown in Figure 3. The numbers (1)-(4)indicate the selected vehicle type and the different driving condition of the vehicle and represent the relevant information of the tractor and trailer, respectively, these four parts constitute the semitrailer model in TruckSim, which is then sent to Simulink through (5) and conduct a co-simulation between (6) and (7); the final simulation results are shown in (8). A semitrailer model with the parameters listed in Table 1 is built from Trucksim library.

Two different manoeuvres with two different steering inputs corresponding two different constant forward speeds are performed in this paper to validate the proposed approach. Detailed simulation analysis is carried out as follows.

In the first manoeuvre, the semitrailer is simulated with a steering input, as shown in Figure 4, at the initial longitudinal velocity $(70 \mathrm{~km} / \mathrm{h})$. Roll angle estimation results are illustrated in Figure 5. The above simulation results show that when the unscented Kalman filter algorithm is used to estimate the roll angle of tractor and trailer simultaneously, the estimation result of trailer is more accurate, but the estimation error of tractor is smaller. This may be due to the coupling effect between the trailer and the tractor. Fortunately, this will not have much impact on the result of rollover warning because the rollover of semitrailer is mainly caused by the rollover angle of the trailer, which can be eliminated by setting the different weight of tractor and trailer rollover angle in the total rollover index reasonably. Therefore, by 


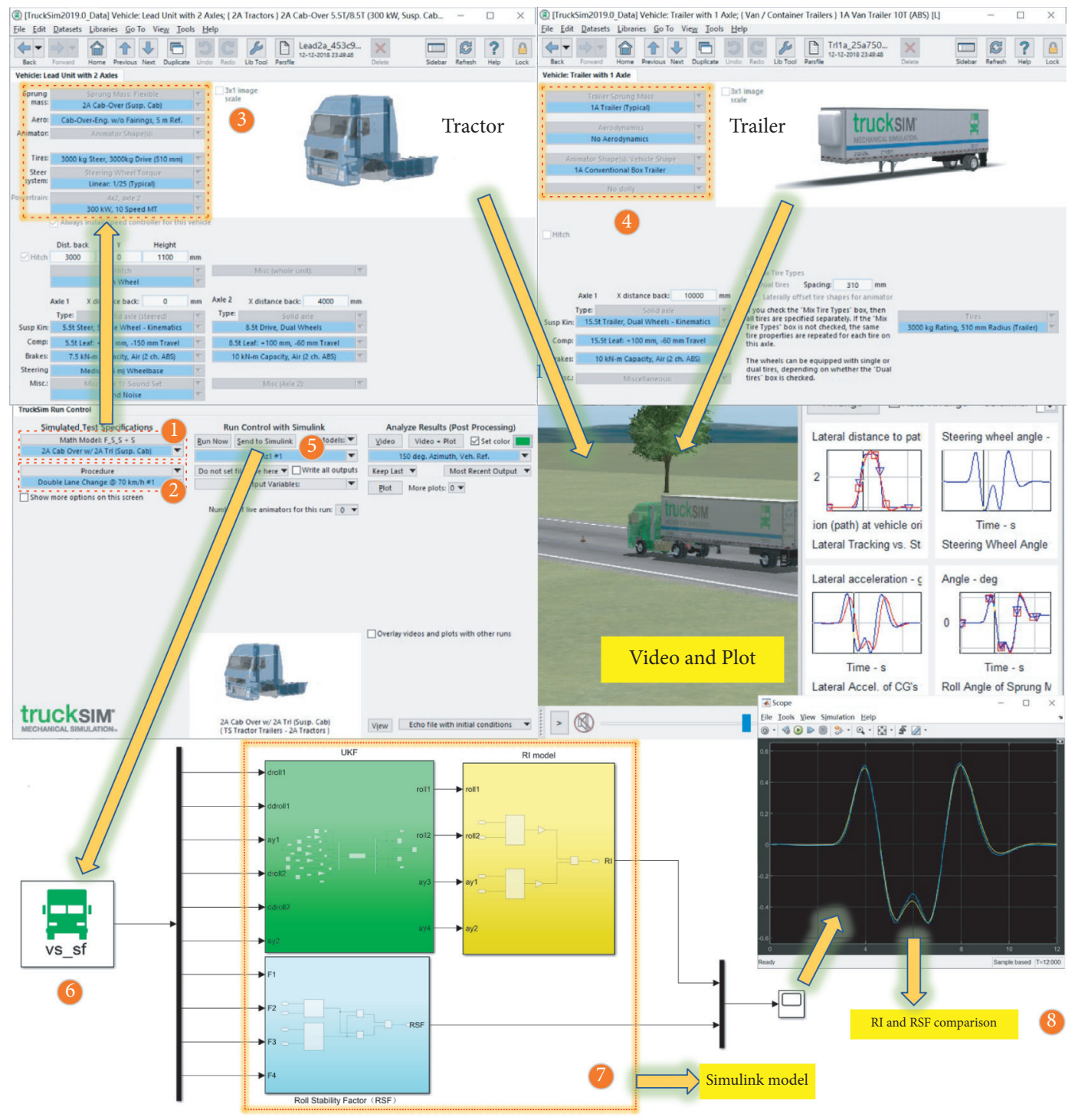

FIGURE 3: Matlab/TruckSim co-simulation diagram.

TABLE 1: Semitrailer vehicle parameters used in simulation.

Parameter

Value/unite

Tractor sprung mass $\left(m_{s}\right)$, trailer unsprung mass $\left(m_{u}\right)$, tractor roll moment of sprung mass $\left(\mathrm{I}_{1 \mathrm{xx}}\right)$, trailer roll moment of sprung mass $\left(\mathrm{I}_{2 \mathrm{xx}}\right)$, tractor CG height $\left(h_{1}\right)$, trailer CG height $\left(h_{2}\right)$, tractor wheelbase $\left(l_{s 1}\right)$, trailer wheelbase $\left(l_{s 3}\right)$, and $4455 \mathrm{~kg}, 6000 \mathrm{~kg}, 2283.9 \mathrm{~kg}^{*} \mathrm{~m}^{2}, 10140 \mathrm{~kg}^{*} \mathrm{~m}^{2}, 1.175 \mathrm{~m}$, $1.935 \mathrm{~m}, 2.03 \mathrm{~m}, 1.863 \mathrm{~m}$, and $1000 \mathrm{~N}^{*} \mathrm{~s} / \mathrm{m}$ suspension damper $\left(b_{s}\right)$

appropriately selecting the weights of tractors and trailers, respective, then the roll index RI can be obtained as follows:

$$
R I=0 \cdot 3 \times R I_{1}+0 \cdot 7 \times R I_{2} .
$$

Substitute the previously estimated roll angle results into the rollover index (31), and compare with the rollover index obtained from the TruckSim using equation (15). It can be seen from the comparison results in Figure 6 that the proposed rollover warning index can well track the given reference value, which indicates the effectiveness of the proposed method.

In the second manoeuvre, the semitrailer is simulated with a steering input, as shown in Figure 7, at the initial longitudinal velocity $(50 \mathrm{~km} / \mathrm{h})$. The simulation results are shown in Figures 8 and 9.

Note that the proposed rollover index still demonstrates good performance when encountering time-varying longitudinal speed and different steering inputs. The above simulation results show the effectiveness of the proposed 


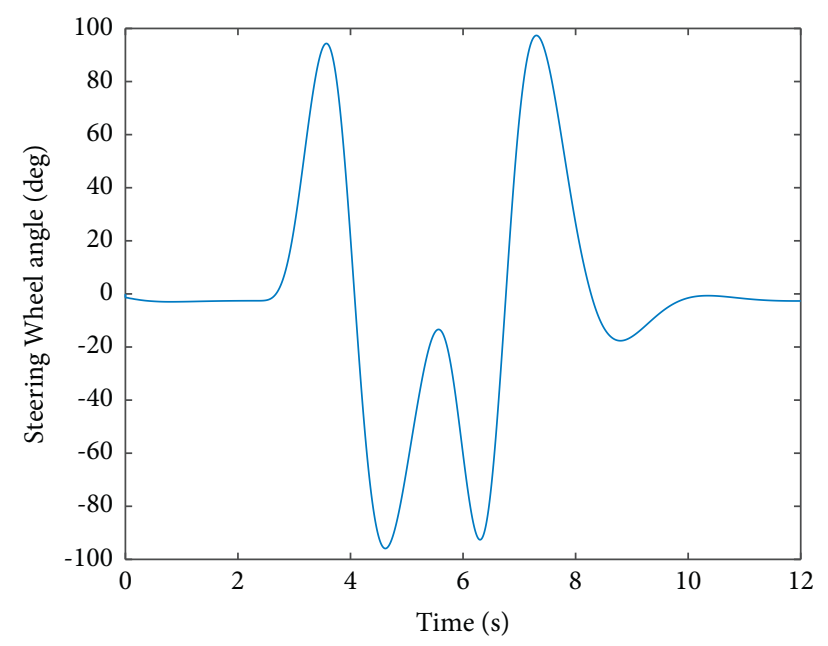

FIgURE 4: Steering input.

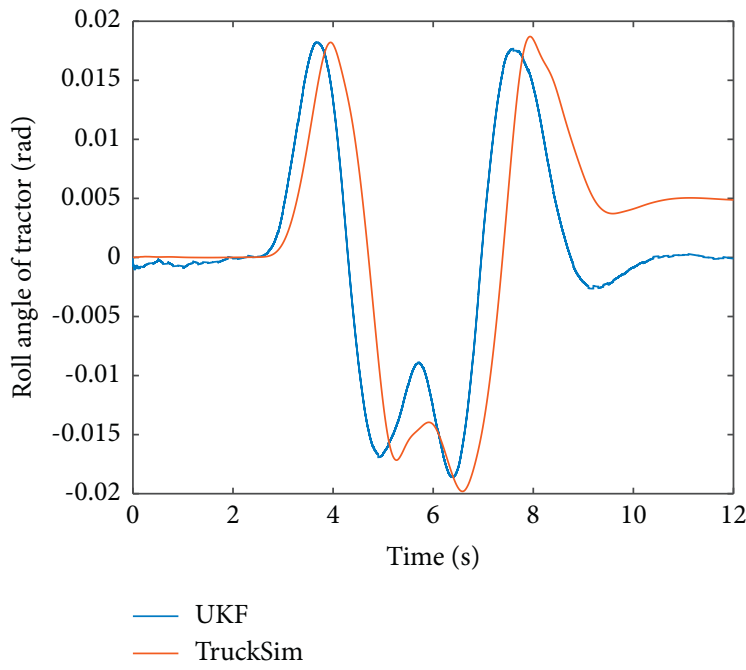

(a)

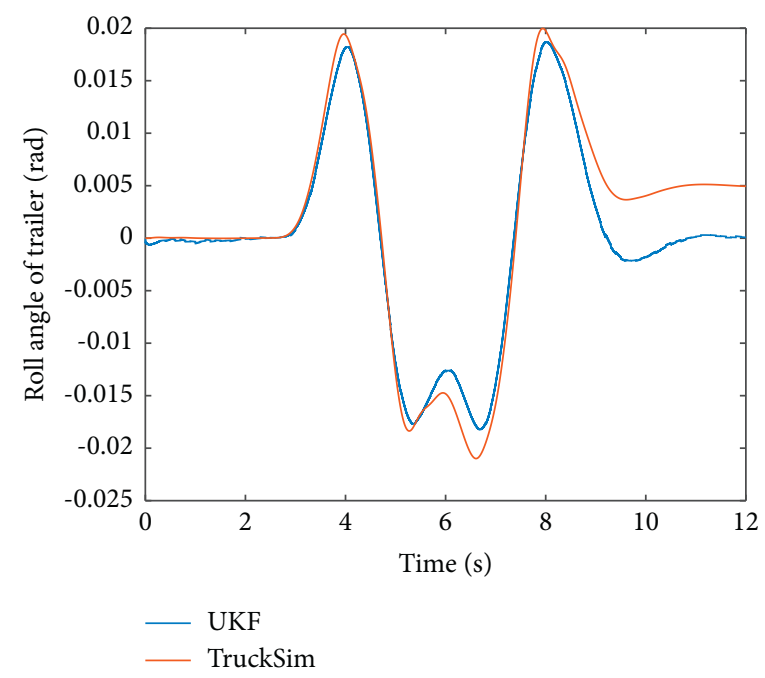

(b)

Figure 5: Roll angle estimation results. (a) Tractor roll angle estimation result. (b) Trailer roll angle estimation result.

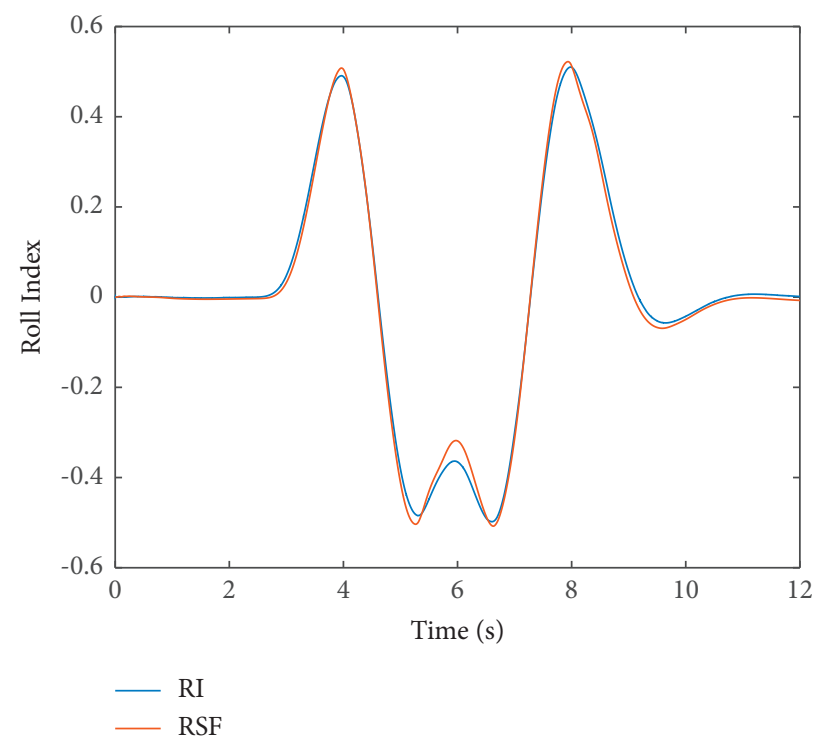

Figure 6: Comparison results of proposed RI and RSF. 


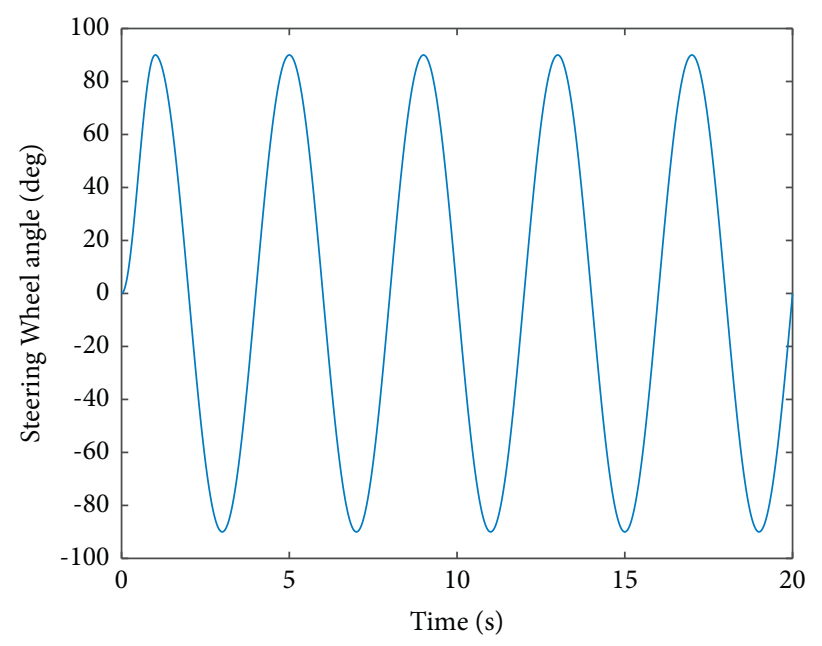

Figure 7: Steering input.

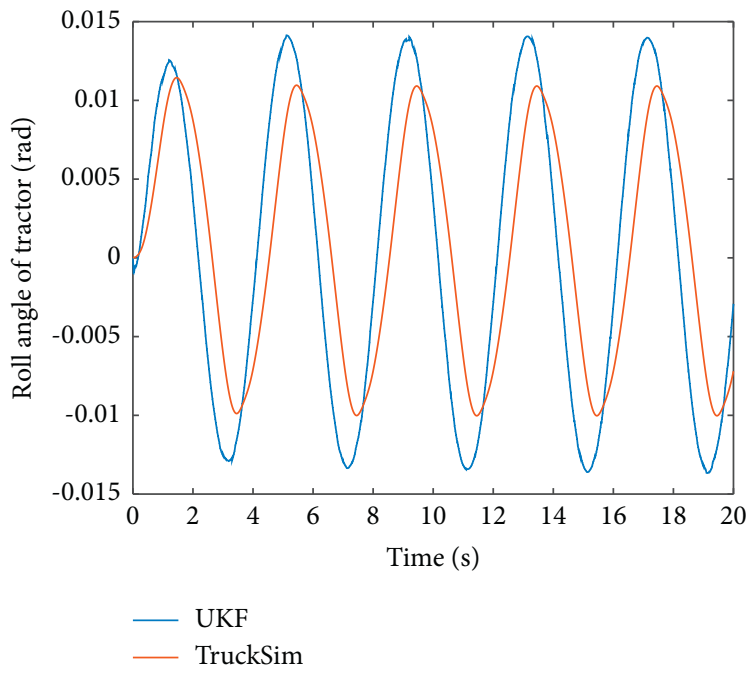

(a)

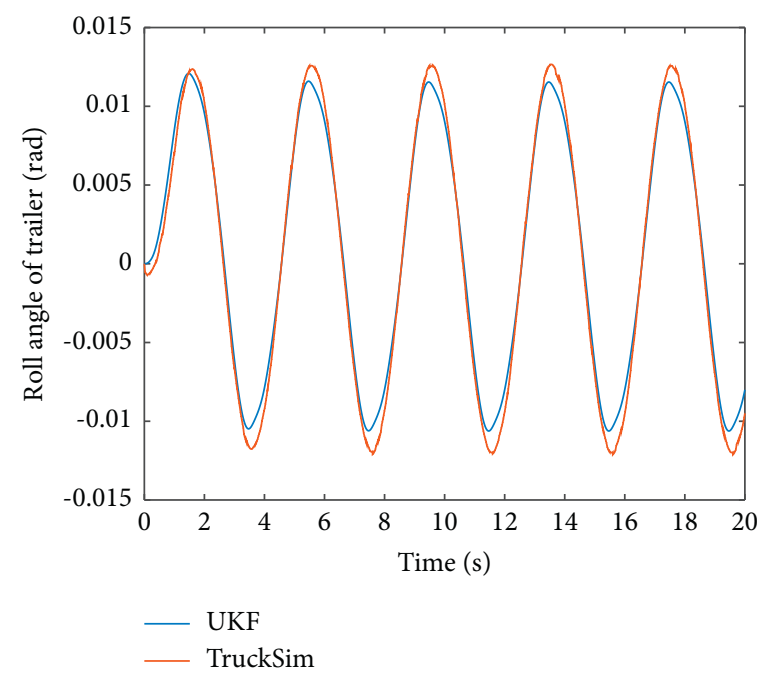

(b)

FIgURE 8: Roll angle estimation results. (a) Tractor roll angle estimation result. (b) Trailer roll angle estimation result.

rollover index, which will lay a prerequisite foundation for the future antiroll control design.

5.2. Implementation Discussion. The implementation of the proposed rollover warning approach for commercial vehicles mainly includes the following three aspects:

Step 1: calculation onset of potential rollover through online monitoring of the designed rollover index

Step 2: compare with the set threshold and trigger the warning signal to the driver

Step 3: a corrective action to be acted by the driver

Since the proposed rollover index ignores the contribution of the front axle of the tractor to the restoring torque, there may be some errors in the prediction of an impending rollover. In view of this fact, a two-stage rollover warning approach based on online monitoring of the proposed rollover index and the roll angle of the trailer is adopted, as shown in Figure 10.

In Figure 10, $\phi_{2}$ represents the roll angle of the trailer. The reason why roll angle $\phi_{2}$ is used as the second evaluation index here is that roll angle $\phi_{2}$ plays a dominant role in the roll of the semitrailer. If the roll angle $\phi_{2}$ exceeds the threshold, the probability of the semitrailer rolling is very high. The minimum and mean values of the rollover thresholds M1, N1, M2, and N2 can be obtained corresponding to the design and operating parameters of related commercial vehicle. Minimum values can be implemented to trigger the visual warning, which would be followed by audio warning when the mean threshold values are reached.

The first state warning is triggered only if both measurements exceed their respective initial threshold limits, which will reduce the possibility of early false warnings. 


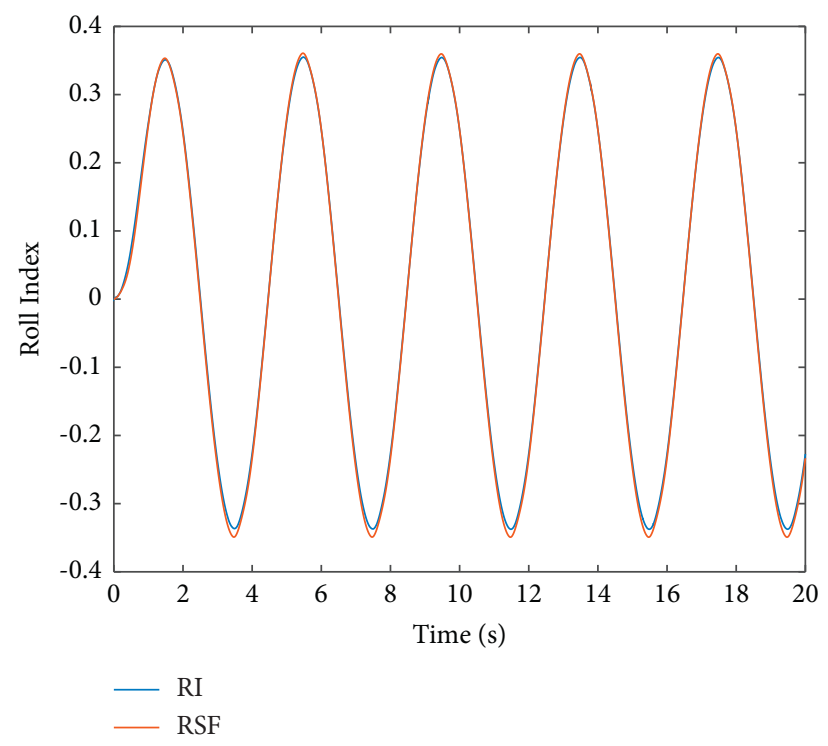

FIgURE 9: Comparison results of proposed RI and RSF.

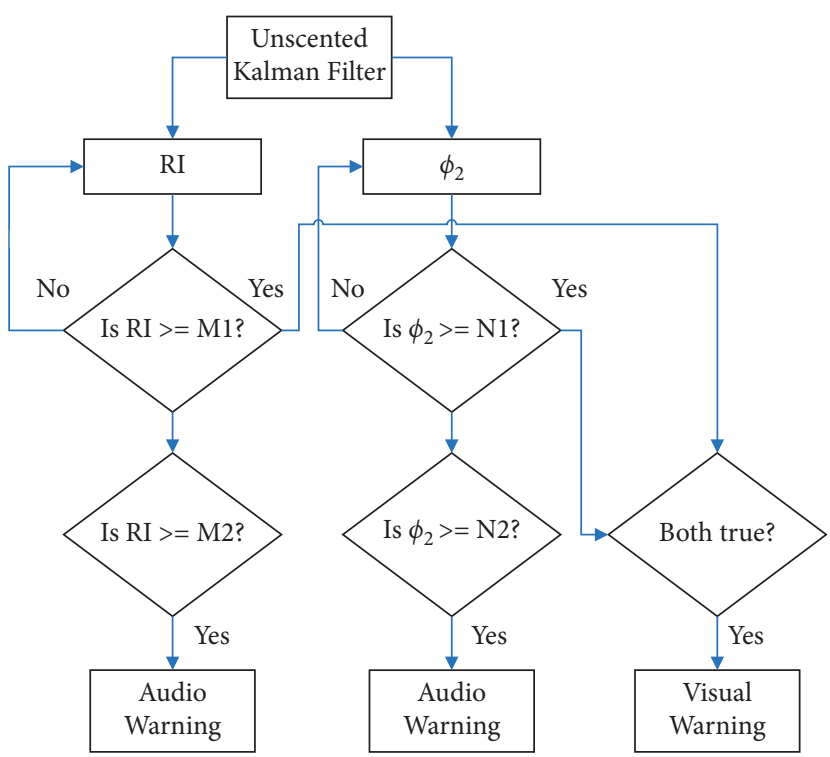

FIgURE 10: A two-stage rollover warning approach.

When either of the two measurements exceeds the final threshold limit, a second-stage warning is generated regardless of the other measurements. This would enhance the timeliness and reliability of warning.

\section{Conclusion}

The roll responses of a commercial vehicles form the essential basis for developing a strategy for predicting impending roll instability. This study reported a novel rollover index based on the roll angle of the tractor and the trailer of a semitrailer. To overcome the poor measurability and sensitivity to variations in vehicle design and operating parameters, unscented Kalman filter is used to estimate the roll angles in the rollover index online. In addition, different weights in terms of roll angles of the tractor and the trailer are considered to overcome the influence of coupling between the tractor and the trailer. Finally, a two-stage rollover warning method is present. Co-simulation results verify the effectiveness of the proposed rollover warning approach. Based on the rollover warning results, a more effective rollover prevention system for heavy commercial vehicles will be developed in the future research.

\section{Nomenclature}

$m_{1}:$ Tractor mass $(\mathrm{kg})$

$m_{2}$ : Trailer mass $(\mathrm{kg})$

$m_{1 s}:$ Tractor sprung masses $(\mathrm{kg})$

$m_{2 s}$ : Trailer sprung masses $(\mathrm{kg})$ 
$u$ : Longitudinal speed of the vehicle $(\mathrm{m} / \mathrm{s})$

$\beta_{1}$ : Tractor side slip angle (rad)

$\beta_{2}$ : Trailer side slip angle $(\mathrm{rad})$

$\omega_{r 1}$ : Tractor yaw rate $(\mathrm{rad} / \mathrm{s})$

$\omega_{r 2}$ : Trailer yaw rate $(\mathrm{rad} / \mathrm{s})$

$h_{1}$ : The distance from the center of mass of the tractor to its roll axis $(\mathrm{m})$

$h_{2}$ : The distance from the center of mass of the trailer to its roll axis $(\mathrm{m})$

$h_{1 c}$ : The distance from the articulation point to the tractor roll axis $(\mathrm{m})$

$h_{2 c}$ : The distance from the articulation point to the trailer roll axis $(\mathrm{m})$

$\phi_{1}: \quad$ Tractor roll angle $(\mathrm{rad})$

$\phi_{2}$ : Trailer roll angle (rad)

$k_{1}$ : Tractor front axle cornering stiffness $(\mathrm{N} / \mathrm{rad})$

$k_{2}$ : Tractor rear axle cornering stiffness $(\mathrm{N} / \mathrm{rad})$

$k_{3}$ : Trailer axle cornering stiffness $(\mathrm{N} / \mathrm{rad})$

$k_{r 1}$ : Tractor roll stiffness $(\mathrm{N} * \mathrm{~m} / \mathrm{rad})$

$k_{r 2}$ : Trailer roll stiffness $(\mathrm{N} * \mathrm{~m} / \mathrm{rad})$

$k_{12}$ : The fifth axle roll stiffness $(\mathrm{N} * \mathrm{~m} / \mathrm{rad})$

$c_{1}$ : Tractor roll damping $(\mathrm{N} * \mathrm{~m} * \mathrm{~s} / \mathrm{rad})$

$c_{2}$ : Trailer roll damping $(\mathrm{N} * \mathrm{~m} * \mathrm{~s} / \mathrm{rad})$

$a$ : The distance from the front axle to the center of mass of the tractor $(\mathrm{m})$

$b$ : The distance from the rear axle to the center of mass of the tractor $(\mathrm{m})$

c: The distance from the articulated point to the center of mass of the tractor $(\mathrm{m})$

$d$ : The distance from the rear axle to the center of mass of the trailer $(\mathrm{m})$

$e: \quad$ The distance from the articulated point to the center of mass of the trailer $(\mathrm{m})$

$I_{1 x x}$ : The moment of inertia of the tractor around the $X$-axis $\left(\mathrm{kg} * \mathrm{~m}^{2}\right)$

$I_{2 x x}$ : The moment of inertia of the trailer around the $X$-axis $\left(\mathrm{kg} * \mathrm{~m}^{2}\right)$

$I_{1 z z}$ : The moment of inertia of the tractor around the $Z$-axis $\left(\mathrm{kg} * \mathrm{~m}^{2}\right)$

$I_{2 z z}$ : The moment of inertia of the trailer around the $Z$-axis $\left(\mathrm{kg} * \mathrm{~m}^{2}\right)$

$I_{1 x z}$ : The yaw product of inertia of the tractor around the center of mass $\left(\mathrm{kg} * \mathrm{~m}^{2}\right)$

$I_{2 x z}$ : The yaw product of inertia of the trailer around the center of mass $\left(\mathrm{kg} * \mathrm{~m}^{2}\right)$.

\section{Data Availability}

The underlying data supporting the results of the study can be obtained from the corresponding author upon request.

\section{Conflicts of Interest}

The authors declare that there are no conflicts of interest regarding the publication of this article.

\section{Acknowledgments}

This work was supported by the National Natural Science Foundation of China (Grant no. 62073298), Key Scientific and Technological Project of Henan Province (Grant nos. 212102310454 and 202102210290), and 2021 National College Student Innovation and Entrepreneurship Training Program Project (Grant no. 202110462011).

\section{References}

[1] Y. He, X. Yang, and X. Lu, "A review of anti-rollover prediction and control technologies for heavy-duty vehicles," Journal of Transport Information and Safety, vol. 37, no. 4, pp. 1-9, 2019.

[2] Z. Ye, W. Xie, Y. Yin, and Z. Fu, "Dynamic rollover prediction of heavy vehicles considering critical frequency," Automotive Innovation, vol. 3, no. 3, pp. 158-168, 2020.

[3] K. Shao, J. Zheng, B. Deng, K. Huang, and H. Zhao, "Active steering control for vehicle rollover risk reduction based on slip angle estimation," IET Cyber-systems and Robotics, vol. 2, no. 3, pp. 132-139, 2020

[4] S. Zhang, S. Bei, B. Li, Y. Zhang, and X. Zhang, "Simulation analysis of vehicle rollover model based on energy method," International Core Journal of Engineering, vol. 5, no. 12, pp. 191-200, 2019.

[5] K. Shao, J. Zheng, and K. Huang, "Robust active steering control for vehicle rollover prevention," International Journal of Modelling, Identification and Control, vol. 32, no. 1, 2019.

[6] R. Rajamani, Vehicle Dynamics and Control, Springer, Berlin, Germany, 2012.

[7] E. Gindy, "An overview of performance measures for heavy commercial vehicles in north America," Int. J. of Vehicle Design, vol. 16, no. 4-5, pp. 441-463, 1995.

[8] L. Palcovics, A. Semsey, and E. Gerum, "Rollover prevention system for commercial vehicles-additional sensorless function of electronic braking system," Intl. Symp. on Advanced Vehicle Control-AVEC, vol. 98, pp. 311-316, 1998.

[9] Z. Jin, J. Li, and Y. Huang, "Study on rollover index and stability for a triaxle bus," Chinese Journal of Mechanical Engineering, vol. 32, no. 1, pp. 1-15, 2019.

[10] S. Rakheja, A. Ahmed, and P. Liu, "Detection of dynamic roll instability of heavy vehicles for open loop rollover control," Heavy Vehicle and Highway Dynamics, SAE SP-, vol. 1308, pp. 105-112, 1997.

[11] S. Kar, S. Rakheja, and A. K. W. Ahmed, "A normalised measure of relative roll instability for open-loop rollover warning," International Journal of Heavy Vehicle Systems, vol. 13, no. 1-2, pp. 74-97, 2006.

[12] L. P. González, S. S. Sánchez, J. G. Guzman, and M. J. Boada, "Simultaneous estimation of vehicle roll and sideslip angles through a deep learning approach," Sensors, vol. 20, no. 13, 2020.

[13] V. M. Leandro, B. Beatriz, B. María, G. Antonio, and D. Vicente, "A sensor fusion method based on an integrated neural network and kalman filter for vehicle roll angle estimation," Sensors, vol. 16, no. 9, 2016.

[14] L. Zhao, Z. Liu, and B. Shen, "Vehicle velocity and roll angle estimation with road and friction adaptation for four-wheel 
independent drive electric vehicle," Mathematical Problems in Engineering, vol. 2014, Article ID 801628, 11 pages, 2014.

[15] M. Mazhar, M. Khan, A. Bhatti, and N. Naseer, "A novel roll and pitch estimation approach for a ground vehicle stability improvement using a low cost IMU," Sensors, vol. 20, no. 2, pp. 1-30, 2020.

[16] L. Xiong, X. Xia, Y. Lu et al., "IMU-based automated vehicle body sideslip angle and attitude estimation aided by GNSS using parallel adaptive kalman filters," IEEE Transactions on Vehicular Technology, vol. 69, no. 10, Article ID 10668, 2020.

[17] C. Cheng and D. Cebon, "Parameter and state estimation for articulated heavy vehicles," Vehicle System Dynamics, vol. 49, no. 1-2, pp. 399-418, 2011.

[18] V. T. Vu, O. Sename, L. Dugard, and P. Gaspar, "H $\infty / L P V$ controller design for an active anti-roll bar system of heavy vehicles using parameter dependent weighting functions," Heliyon, vol. 5, no. 6, Article ID e01827, 2019.

[19] Z. Jin, C. Wang, and L. Zhang, "Rollover prevention for a heavy vehicle using optimised slide mode steering control," International Journal of Heavy Vehicle Systems, vol. 26, pp. 3-4, 2019.

[20] F. Yakub and R. Mori, "Heavy vehicle stability and rollover prevention via switching model predictive control," Int. J. Innovative Computing, Information and Control, vol. 11, no. 5, pp. 1751-1764, 2015.

[21] R. Kamnik, F. Boettiger, and K. Hunt, "Roll dynamics and lateral load transfer estimation in articulated heavy freight vehicles," Proceedings of the Institution of Mechanical Engineers - Part D: Journal of Automobile Engineering, vol. 217, no. 11, pp. 985-997, 2003.

[22] X. Huang and J. Wang, "Longitudinal motion based lightweight vehicle payload parameter real-time estimations," Trans. ASME, J. Dyn. Syst. Meas. Control, vol. 135, no. 1, pp. 1-10, 2013.

[23] Y. Zhang, J. Ma, X. Zhao, X. Liu, K. Zhang, and X. Shao, “A modified unscented kalman filter combined with ant lion optimization for vehicle state estimation," Mathematical Problems in Engineering, vol. 2021, Article ID 8847075, 21 pages, 2021. 